\title{
Light stimulates swimming behavior of larval eastern oysters (Crassostrea virginica) in turbulent flow
}

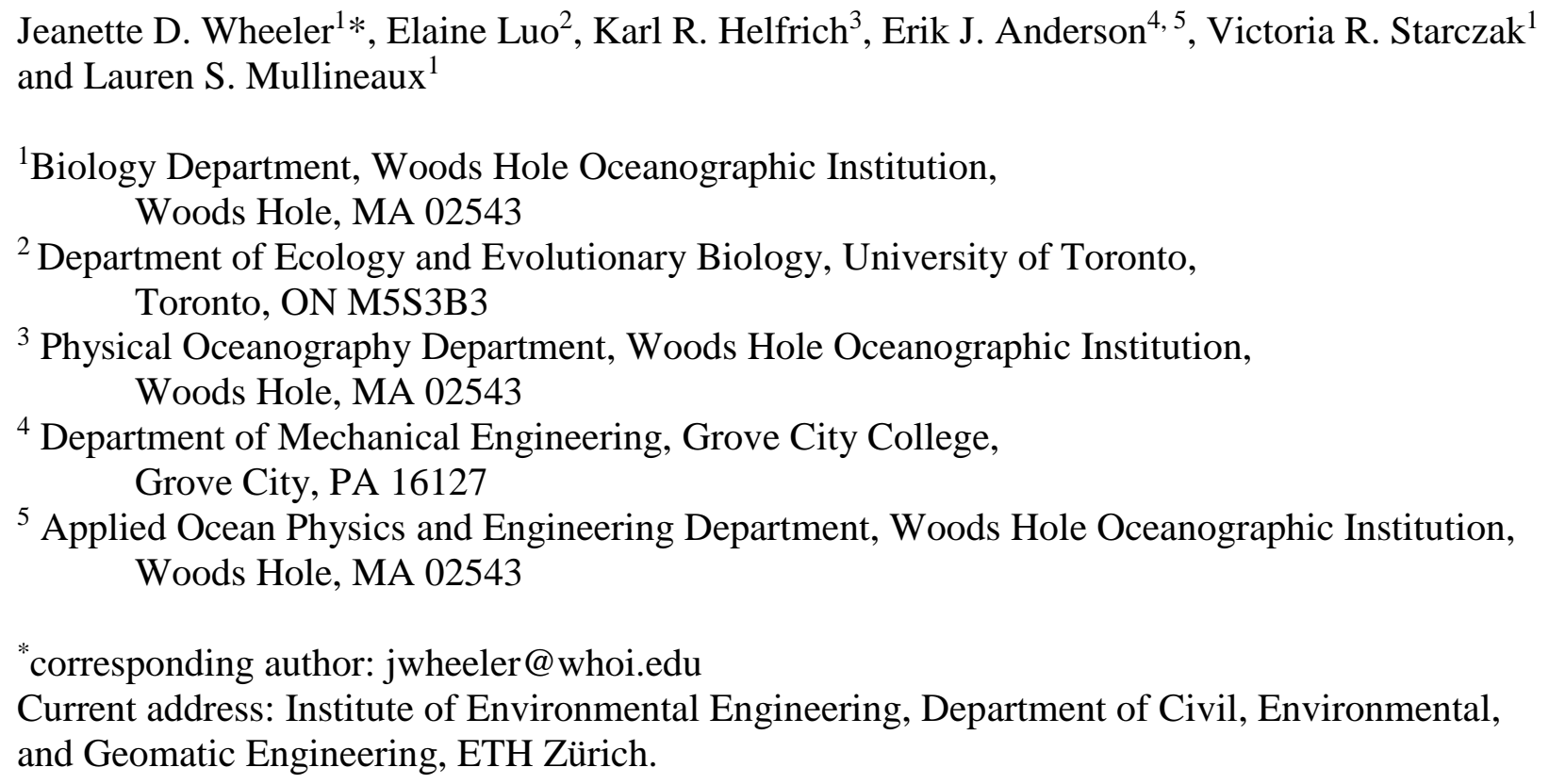

Running page head: Oyster larvae respond to light

Keywords: larval invertebrate ecology, larval swimming, environmental cues, hydrodynamics

\section{Abstract}

Planktonic larvae of the eastern oyster (Crassostrea virginica) are able to regulate their vertical

27 position in the water, but the environmental cues responsible for this regulation, particularly in turbulent settings, remain unclear. We quantified swimming responses of late-stage oyster larvae in a grid-stirred turbulence tank to determine how light affects the swimming behavior of larvae over a range of hydrodynamic conditions similar to their natural coastal environments.

31 We used particle image velocimetry and larval tracking to isolate larval swimming from local

32 flow and to quantify three behavioral metrics: vertical swimming direction, proportion of larvae

33 diving, and proportion of larvae swimming helically. We compared these metrics across 
34 turbulence levels ranging from still water $\left(\varepsilon=0 \mathrm{~cm}^{2} \mathrm{~s}^{-3}\right)$ to estuarine-like conditions $\left(\varepsilon=0.4 \mathrm{~cm}^{2}\right.$

$35 \mathrm{~s}^{-3}$ ) in light and dark. In all turbulence levels, light had no effect on the proportion of upward 36 swimming larvae, but elicited detectable increases in the proportion of helical swimming and

37 diving behaviors. We further examined the effect of light and turbulence on specific

38 characteristics of helical trajectories, and found that these environmental cues induce changes to

39 both vertical and horizontal velocities of helically swimming larvae, changing the helix

40 geometry. The increased prevalence of these behaviors in light likely plays an ecological role:

41 increased diving in light (in conjunction with turbulence) is a potential mechanism to enhance

42 settlement success, while changes to helical swimming in light may serve an anti-predatory

43 function. Together, these behaviors provide insight into potentially complex larval responses to

44 multiple simultaneous environmental cues.

\section{$47 \quad 1$ Introduction}

The eastern oyster (Crassostrea virginica), like many benthic marine invertebrates, is

50 spawned into the water column and develops through a series of free-swimming planktonic

51 larval stages prior to settlement to the benthos. Adult populations of oysters have high economic

52 value through shellfisheries and aquaculture (Newell 1988, Breitburg et al. 2000), as well as less

53 readily quantifiable benefits such as large-scale water filtration (Nelson et al. 2004) and shoreline

54 stabilization (Currin et al. 2010). Oyster populations have declined to $1 \%$ of historical biomass

55 due to a combination of overharvesting and long-term environmental changes (Rothschild et al.

56 1994, Kemp et al. 2005), and efforts at population restoration and conservation require us to 
57 study oysters at the vulnerable larval stages. Understanding larval behavior during planktonic

58 stages is important for both dispersal modelling (North et al. 2008, Metaxas and Saunders 2009,

59 Kim et al. 2013) and effective population restoration via larval supply; the competent-to-settle

60 larval stage is of particular interest, as successful larval recruitment is crucial to adult survival

61 and reproduction (Butman 1987, Bartol et al. 1999, Nestlerode et al. 2007). Larval oyster

62 recruitment in particular relies on larvae locating preferred settlement sites in shallow water on

63 rough substrate (NOAA 2007).

64

65 Previous studies have shown strong correlations between physical habitat and oyster

66 larval recruitment (Fredriksson et al. 2010, Whitman and Reidenbach 2012), suggesting that

67 settlement habitats impart variable mortality or that environmental cues in the water column

68 above suitable settlement habitats may mediate larval behavior. Both explanations likely factor

69 into larval recruitment success, and the second explanation has been a continuing source of

70 interest to larval ecologists. Indeed, larval oysters have long been known to use chemical cues

71 released by adult oysters to initiate settlement (Tamburri et al. 1996), and more recent work

72 suggests a possible role of acoustic signatures typical of oyster reefs (Lillis et al. 2013).

73 Additionally, oyster larvae appear to respond to turbulence with a range of behaviors: larval

74 eastern oysters have been reported to increase downward swimming (Fuchs et al. 2013), upward

75 swimming (Wheeler et al. 2013) and diving (Wheeler et al. 2015) with changes in local flow

76 conditions.

77

Whether light plays a role in the regulation of larval oyster swimming and settlement

79 behavior remains unclear. Larval oysters are negatively buoyant and need to swim upwards to 
80 maintain position in the water column, exhibiting negative gravitaxis and possibly positive

81 phototaxis (Hidu and Haskin 1978, Kennedy 1996). Responses to light have been widely

82 reported in larvae of other marine groups such as gastropods (Bingham and Young 1993),

83 crustaceans (Forward and Cronin 1980, Wu et al. 1997), and ascidians (Svane and Young 1989,

84 Vazquez and Young 1998). Further, responses to light vary with ontogeny (Young and Chia

85 1982, Vazquez and Young 1998). Oyster larvae may exhibit ontogenetic switching in

86 phototactic responses: while early stage larvae remain high in the water column, late-stage

87 pediveligers that are competent to settle into a benthic habitat could potentially display negative

88 phototaxis to move downward in the water column. It is unclear at present if light influences

89 settlement success and metamorphosis in larval oysters; confounding effects such as temperature

90 and turbidity may account for contradictory results in the literature (see Kennedy (1996) for

91 review).

92

As addressed above, most investigations of larval behavioral changes in light focus on

94 vertical swimming direction as a positive or negative phototactic response. A less well studied

95 question is whether other non-directional characteristic behaviors of larvae change significantly

96 with light, as these responses can likewise affect larval positioning in the water column.

97 Competent larval oysters are especially useful for investigating this question, due to distinct

98 behaviors such as helical swimming (exploratory corkscrew swimming trajectories) and diving

99 (transient rapid downward acceleration) that can be readily observed and compared between light

100 and dark regimes. Our study aims to quantify the swimming responses of oyster pediveligers to

101 light, and determine whether these responses vary over a range of turbulence conditions typical

102 of their natural coastal environment. This dual-factor approach allows us to explore turbulence 
103 thresholds of light-induced behaviors, and to evaluate whether particular larval responses might 104 occur more commonly in day or night time conditions. We also investigate the potential utility 105 of light as a cue to enhance settlement success in larvae. Larval behavior is quantified by 106 observing the proportion of larvae: 1) swimming upward, 2) diving, and 3) swimming helically. 107 Larval vertical swimming is of interest because it provides a broad indicator for active 108 settlement. Diving is an active behavior that larvae may use for either settlement or predation 109 escape (e.g., Finelli and Wethey 2003, Wheeler et al. 2015), whereas helical swimming may be 110 used in exploration or feeding (e.g., Jonsson et al. 1991, Visser 2007).

\section{Methods}

\subsection{Larval Culture}

119 from rearing larvae from multi-generation brood stock cannot be ruled out, but the benefits of 120 commercial larvae instead of wild-caught larvae include their good-health, known history, and

121 availability in large quantities $\left(10^{5}-10^{6}\right.$ larvae). Larvae were maintained in $3 \mu \mathrm{m}$-filtered, aerated 122 seawater at ambient field temperature $\left(20-22^{\circ} \mathrm{C}\right)$ and salinity $(33 \mathrm{psu})$, in covered $16 \mathrm{~L}$ plastic 123 buckets. Larvae were kept at low densities $\left(<3\right.$ larvae $\left.\mathrm{mL}^{-1}\right)$ to minimize interactions and 124 harmful metabolite build-up (Helm et al. 2004) and fed daily a suspension of haptophyte 125 Isochrysis $\mathrm{sp} .\left(\sim 9 \times 10^{5}\right.$ cells $\mathrm{mL}^{-1}$ in filtered seawater $)$. Experimental trials were conducted 
Oyster larvae respond to light

126

127

128

129

130

131

132

133

134

135

136

137

138

139

140

141

142

143

144

145

146

147

148

within 2 days of larval acquisition, during which $>80 \%$ of the larvae were observed to have eyespots (a common indicator of competency, Thompson et al. 1996).

\subsection{Experimental setup}

The experiments were conducted in a grid-stirred turbulence tank $(44.5 \times 44.5 \times 90 \mathrm{~cm}$; described in Wheeler et al. 2013), filled with $3 \mu \mathrm{m}$-filtered seawater at $\sim 20^{\circ} \mathrm{C}$, in a temperaturecontrolled chamber at $20^{\circ} \mathrm{C}$. The two horizontal grids, separated vertically by $45 \mathrm{~cm}$, were constructed of $1 \times 1 \mathrm{~cm}$ acrylic bars spaced $5 \mathrm{~cm}$ apart. The grids were attached to a drive rod that oscillated them vertically in phase with an amplitude of $5 \mathrm{~cm}$ at a specified frequency. While grid-stirred turbulence lacks the strong vertical shear of the bottom boundary layer, it is a good system for characterizing larval behavior $>10 \mathrm{~cm}$ above the bottom and investigating responses in the absence of large scale velocity gradients. In the light treatment, our visible light source (2700K, PAR of $40.93 \mu \mathrm{E} \mathrm{m}^{-2} \mathrm{~s}^{-1}$ at water surface) was placed on top of the tank and directed downwards to emulate the direction of light experienced by larvae in nature. This irradiance is characteristic of larval phototaxis studies (e.g., Forward and Cronin 1980, Bingham and Young 1993, Fuchs and Dibacco 2011) although likely lower than would be experienced by larvae in the field (Frouin et al. 2012).

For each experimental trial, larvae were gently introduced into the tank at densities of 0.36-0.6 larvae $\mathrm{mL}^{-1}$. The tank was then seeded with neutrally buoyant polystyrene particles (3.0-3.4 $\mu \mathrm{m}$ diameter, Spherotech) to a density of $\sim 4.2 \times 10^{4}$ particles $\mathrm{mL}^{-1}$ for flow characterization by particle image velocimetry (PIV). A monochrome high-speed camera (Photron Fastcam SA3, 1024 x 1024 pixel resolution), was focused on a $~ 3$ x $3 \mathrm{~cm}$ field of view 
149 in the center of the tank, equidistant from the grids. Larval diameters were approximately 2

150 orders of magnitude smaller than the dimensions of the field of view, where individual larvae

151 were $\sim 10$ pixels wide. A near-infrared laser (Oxford Lasers, Firefly 300W, 1000Hz, 808 nm),

152 oriented perpendicularly to the camera, illuminated the field of view with a laser sheet unaffected

153 by the presence or absence of visible light. The e-folding depth of the laser sheet was

154 approximately $1 \mathrm{~mm}$ and the detection depth of the sheet for clear imaging of the large, bright

155 larvae was approximately $2.5 \mathrm{~mm}$.

156 The larvae were subjected to either dark or light conditions under 5 turbulence levels,

157 ranging from unforced flow $\left(\varepsilon=0 \mathrm{~cm}^{2} \mathrm{~s}^{-3}\right)$ and low turbulence $\left(\varepsilon=0.002 \mathrm{~cm}^{2} \mathrm{~s}^{-3}\right)$ to conditions

158 similar to coastal estuarine zones $\left(\varepsilon=0.4 \mathrm{~cm}^{2} \mathrm{~s}^{-3}\right)$, with energy dissipation rates estimated as in

159 Wheeler et al. (2013). After larvae and particles were introduced, the tank was permitted a 20-

160 minute relaxation period, with the still water (unforced) treatment conducted after this period.

161 Video sequences, recorded at 60 frames per second, were collected for each turbulence level.

162 These video sequences ranged from $135 \mathrm{~s}$ total duration in the highest turbulence level to $225 \mathrm{~s}$

163 duration in the lowest (where larval paths through the field of view were least frequent). In each

164 turbulence level, the record was broken into 45-s intervals, separated by 5 min, to allow the

165 camera to download the images.

Four replicate trials for the light and dark conditions, each with a separate batch of

167 larvae, were conducted by cycling through all 5 turbulence levels. The turbulence levels were

168 sequenced in a different order, in a Latin square configuration post-unforced flow, in each trial

169 (Table 1, Table S1) to reduce possible confounding temporal effects.

\section{$171 \quad 2.3$ Local flow subtraction to isolate larval swimming velocities}


174 velocity from the larval motion at each step in the recorded larval trajectory. The essentials of

175 this procedure are described here; full detail is presented in Wheeler et al. (2013). To track larval 176 motion, larval centroid positions were first identified in each frame using custom LabVIEW

177 (National Instruments) software with user-specified tolerances on larval size and pixel intensity. 178 Larvae were then tracked from frame to frame using a custom MATLAB script with a specified 179 maximum search radius in subsequent frames, and frame-to-frame instantaneous velocities were 180 thereby calculated.

To calculate flow velocities local to larvae, flow fields first were estimated using PIV with DaVis v.7.2 (LaVision) software to a spatial resolution of $\sim 0.04 \mathrm{~cm}$ and velocity vector 184 fields were imported into MATLAB. We identified annuli (inner radius $\sim 0.04$ and outer radius 185 $\sim 0.2 \mathrm{~cm}$ ) of flow vectors around each larva and averaged the flow velocity within each annulus. from observed larval velocity at each time step for each larva. Individual instantaneous larval 189 swimming velocity time series were then used to compute the proportion of upward swimming 190 larvae. Individual mean larval velocities were computed by averaging instantaneous velocities 191 over the observed larval trajectory, and a larva was classified as upward swimming if its mean 192 vertical swimming velocity was positive.

\subsection{Identification of dives}


Oyster larvae respond to light

The dive response is a distinct behavior characterized by a rapid downward burst in

197 speed. Dives were identified using larval instantaneous vertical swimming velocity and

198 acceleration time-series, where acceleration was computed from the velocity time-series data

199 using a central difference scheme. A dive was characterized by a sudden (within 1/30 s) drop in

200 vertical velocity, typically lasting approximately one second, during which time the larva slowed

201 its descent and eventually reached near-zero vertical velocity (Fig. 1a). Larval trajectories were

202 classified as dives if they reached an instantaneous acceleration of $3.0 \mathrm{~cm} \mathrm{~s}^{-2}(\sim 100$ body lengths

$\left.203 \mathrm{~s}^{-2}\right)$ for more than one time step $(1 / 60 \mathrm{~s})$, and achieved an instantaneous negative vertical velocity

204 of at least $-0.4 \mathrm{~cm} \mathrm{~s}^{-1}$.

205

206

2.5 Identification of helical swimming

207

The corkscrew shaped path of helically swimming larvae results in a near-sinusoidal

209 curve in horizontal velocities with respect to time. We searched for occasions of helical

210 swimming by detecting sinusoidal-like motion in time-series of larval horizontal swimming

211 velocities. A larva was categorized as helically swimming if it contained at least one sinusoidal

212 peak in horizontal velocity or corrected horizontal position (in which corrected horizontal

213 position was numerically integrated from swimming velocity time series, in order to strip the

214 effects of flow on position). These peaks were determined by visual inspection, and were only

215 accepted as part of a helix if they exhibited a minimum horizontal velocity magnitude of $0.05 \mathrm{~cm}$ $216 \mathrm{~s}^{-1}$ (Fig. 1b). 
Oyster larvae respond to light

218

219

220

221

222

223

224

225

226

227

228

229

230

231

232

233

234 235 data was

236

237

238

240

3
239 of primary interest consist of "light", denoting light versus dark tank conditions, and "turbulence

\subsection{Analysis of behavioral data}

The effects of light and turbulence on the proportion of upward swimming larvae were analyzed in the turbulence regimes and the unforced regime using two separate general linear models. Data were separated into unforced and turbulence analyses because the unforced observations were taken prior to any turbulence observations in all trials, and the turbulence treatments between the trials were amenable to a Latin squares analysis. The purpose of the analysis was to detect effects of light and turbulence, as well as their interaction, on vertical swimming, but we also incorporated unavoidable potential influences on larval behavior, including larval age and time spent in the tank. Within each trial, we assume our estimates for vertical swimming in each turbulence treatment were independent, as the total number of larvae in the tank in each trial $\left(\sim 5-10 \times 10^{4}\right)$ was several orders of magnitude larger than the number of trajectories observed (Table 1, Table S1). Further, the time delay between each video observation within a turbulence treatment increased the likelihood that new larvae were constantly being observed.

The model for $Y$, the proportion of upward swimming larvae, for the turbulence regime

$Y=\mu+$ light + turb. level + turb. level $\times$ light + trial $($ light $)+$ time + time $\times$ light + error

Here $\mu$ and error denote the mean and normally distributed error, respectively. The model terms level", denoting tank oscillating grid frequency. "Trial” denotes the replicate tank fill (4 in total 
241 for each light regime) which also unavoidably encompasses larval aging, due to the time required

242 to conduct the full experiment (approximately 12 hours). "Time", denotes the variable

243 controlling the turbulence treatment order (that is, each turbulence level occurred at a different

244 time within each trial, as the turbulence levels were reordered for each new trial).

The model for the unforced regime data was

246

247

248

249

250

251

252

253

254

255

256

257

258

259

260

261

262

263

6

$$
Y=\mu+\text { light }+ \text { trial(light })+ \text { video seq. }+ \text { light } \times \text { video seq. }+ \text { error. }
$$

In this model, the turbulence and time factors are no longer applicable, but an additional factor "video sequence", was added, which specifies the 45s segment in a full set of video sequences within a turbulence level. This factor was only considered in the unforced model because higher flow regimes used different numbers of video sequences in each turbulence level (Table 1, Table S1). The non-standardized number of video sequences was by design, in order to obtain a more similar number of larval trajectories in each turbulence regime: fewer larval trajectories were observed in lower turbulence treatments and hence more video sequences were taken.

Light (2 levels), turbulence level (4 levels), trial (4 levels), video sequence (4 levels), and time (4 levels) were categorical variables, and light was tested between trials in the light and dark treatments. Other effects were fixed and tested with the mean squares error of the ANOVA within the light and dark treatments individually. 
Oyster larvae respond to light

264 analysis, as helical swimming was only identified in the unforced and lowest forcing regime.

265 This is due to the inherent challenge of identifying a multi-second behavioral pattern (a full

266 helical period) when larvae are rapidly advected through the field of view in more highly

267 turbulent flow. The unforced and low forcing regimes, in contrast, have individual larval

268 trajectories sufficiently long to identify the helical swimming motion. For helix data, analysis on

269 each variable was done with a split plots design with light as the main factor, trials nested within

270 light and turbulence as the subplot factor. In addition to the proportion of helically swimming

271 larvae, we also applied this model to two relevant characteristics of helix geometry: 1) vertical

272 translational velocity (mean vertical swimming speed during an identified half helix) and 2) helix

273 speed (instantaneous swimming speed averaged over a half helix period, or as long as the helix

274 remained in the field of view).

In all analyses, the proportional behavioral metrics were not transformed as no

276 transformations tested increased model fit. Residual analysis further determined that the general

277 linear model was appropriate for our analysis. Factors deemed significant from the ANOVAs

278 were compared post-hoc using Tukey HSD tests for least squares means of behavioral metrics.

2813 Results 
In both light and dark, larvae generally swam downward in the unforced flow regime, upward in moderate turbulence, and displayed decreased upward swimming in high turbulence (Fig. 2). This effect of turbulence was significant in the ANOVA (Table 2) and the post-hoc tests (Table S2). In the turbulence regimes, light had no significant effect on upward swimming, either by itself, or in interaction with time or turbulence level (Table 2), which suggests that larvae did not respond phototactically.

In the turbulent regimes, time (i.e., treatment order within a trial), and trial also had a significant effect on upward swimming (Table 2). Larvae exhibited decreased upward swimming in turbulence levels occurring later in the treatment order, regardless of what these turbulence levels happened to be (Table S3). This could be a consequence of a larval response to an aggregative turbulence cue, acclimation to the tank, or fatigue. Upward swimming decreased over the full experimental time period (Fig. 2, dark to light points), with larvae in later trials generally exhibiting less upward swimming than earlier trials.

In the unforced flow regime, light had no effect on the proportion of upward swimmers (Table 3). In contrast to the turbulence regimes, trial had no significant effect on upward swimming. Video sequence did have a significant effect but it was difficult to interpret. One might reasonably expect video sequence number to act as a proxy for time spent in the tank. However, in examining each trial, there was no robust temporal pattern in upward swimming over the full range of video sequences, and the post-hoc comparison test showed no pairwise significant difference between sequences (Table S4). 
Oyster larvae respond to light 325 light cue.

\subsection{Diving}

\section{$327 \quad 3.3$ Helical swimming}

We observed 367 dives in total, predominantly in the unforced and low turbulence regimes. The proportion of dives was distinctly and consistently higher in the light than dark regime, across all turbulence levels (Fig.3a), but the effect was not statistically significant (Table 4). The difficulty in ascertaining a light response may be due to the low power of the test and a significant variability among trials. The proportion of dives differed significantly between turbulence levels (Table 4), where the proportion of dives was highest in the lowest turbulence treatment and decreased with increasing turbulence (Fig. 3a, Table S5). Further, trial had a significant effect on diving (Table 4), with the proportion of dives increasing in the later trials. a significant effect in conjunction with time (Table 4). In the fourth (and last) turbulence treatment administered within a trial, the proportion of diving larvae was higher in light than in dark (Fig. 3b, Table S6); that is, light became a significant effect at the end of the series of turbulence treatments within a trial. Like with upward swimming, larvae appear to dive in response to an aggregative turbulence cue; in contrast with upward swimming, it also requires a

Helical swimming was more common in light than dark treatments, but the difference was non-significant (Fig. 4a, Table 5). Turbulence negatively affected helical swimming, as a 
331 significantly smaller proportion of larvae swimming helically was observed in the low forcing

332 regime than in the unforced regime (Fig 4a, Table 5). Trial had no impact on helical swimming,

333 and the interactive effect of light and turbulence was also non-significant (Table 5). The

334 decreased proportion of helical swimmers in turbulence appears to be a behavioral response, and

335 not solely an effect of decreased detection as larvae are advected more rapidly through the thin

336 laser sheet in the low forcing regime. Using PIV data from the unforced and low forcing

337 regimes, we estimated average horizontal root mean square (rms) flow velocities of $v_{\text {rms }}=0.04$

$338 \mathrm{~cm} \mathrm{~s}^{-1}$ and $0.11 \mathrm{~cm} \mathrm{~s}^{-1}$, respectively, and average flow autocorrelation timescales of $\tau=7.2 \mathrm{~s}$ and

339 3.6s. Over the average time it took to visually identify a helix $(\sim 1.5 \mathrm{~s})$, estimated ballistic

340 displacements of larvae by turbulent fluctuations were $0.06 \mathrm{~cm}$ and $0.16 \mathrm{~cm}$ in the unforced and

341 low forcing regimes, respectively. As these length scales are smaller than the depth of the laser

342 sheet for larval imaging $(0.25 \mathrm{~cm})$, the helical trajectories are not likely to be systematically

343 undetected in low intensity turbulence. Nevertheless, decreased detection may play a small role

344 in the result and would certainly be exacerbated in more turbulent flow regimes.

While light did not impact the overall proportion of larvae swimming helically, it did

347 affect the mean helix speed, with borderline significance (Fig. 4b, Table 6). Turbulence did not

348 affect helix speed, nor did the interaction between turbulence and light (Table 6). Isolating and

349 testing the translational velocity (the vertical helical swimming velocity) yielded no effect of

350 light (Fig. 4c, Table 7), but a significant turbulence effect and interactive effect of light and

351 turbulence (Fig. 4c, Table 7). Overall, helically swimming larvae swam faster in light than

352 darkness, and vertical translational helical velocity increased with turbulence (Table S7). 


\section{Discussion}

We found no evidence of direct phototaxis in competent-to-settle oyster larvae, as larvae exhibited no change in vertical directional swimming in either unforced flow or across a range of

359 turbulence regimes. In contrast, both turbulence and larval age had strong impacts on larval 360 swimming direction. We found that larvae exhibited distinct increases in dive frequency and 361 increased speed in exploratory helical swimming behavior in the presence of light, suggesting 362 that light encourages specialized exploratory, settlement, and predator-avoidance behavioral 363 modes. Diving and helical swimming were less common in increased turbulence, suggesting a 364 competing effect between light and turbulence in regulating these behaviors.

The effects of light on swimming behavior have several implications for larval ecology,

367 specifically relating to settlement and predator-avoidance. Diving is an active downward 368 acceleration that may enhance settlement (Fuchs et al. 2013, Wheeler et al. 2013, Wheeler et al. 369 2015); larval diving responses occur in the range of turbulence regimes consistent with flow 370 several centimeters above rough bottom topographies (Wheeler et al. 2015, Pepper et al. 2015). 371 Oyster larval settlement in the field has historically been observed to be higher during daylight 372 hours (Medcof 1955); our observations suggest that diving was enhanced by the combined 373 effects of light and an aggregative turbulence cue, wherein larvae in the light regime dove more 374 frequently in the fourth and last turbulence regime experienced, regardless of turbulence 375 intensity. Increased diving in response to a combined light and turbulence cue may help larvae 376 in navigating flow fields over their preferred rough bottom settlement sites and in encountering 
377 said sites during their preferred daylight settlement times. From an anti-predatory perspective,

378 many predators of larval invertebrates use visual cues to detect their prey (Iwasa 1982), and so

379 increasing predator-avoidance behaviors in light versus dark would be a useful survival strategy.

380 Indeed, oyster larvae dive more frequently when exposed to anomalously high local fluid

381 acceleration (Wheeler et al. 2015), which larvae may interpret as the presence of a suction

382 feeding predator (Kiørboe et al. 1999, Jakobsen 2001). Similarly, helical swimming may also act

383 as a predator-avoidance response while simultaneously allowing larvae to feed and explore the

384 water column: helical swimming clears large foraging volumes while presenting a minimal

385 hydromechanical presence to predators (Visser 2007). The increased occurrence of diving and

386 helical swimming in light may reflect the larval response to an increased predation risk during

387 daylight hours.

388

Alternatively, helical swimming may increase the precision of navigation during directional swimming such as phototaxis, as demonstrated in simulations of annelid swimming (Jékely et al. 2008, Jékely 2009). While no phototactic response is obvious in the proportion of upward swimming larvae in our study, the change in helical swimming characteristics in light demonstrates a photokinetic behavior of potential benefit to a directionally swimming larva.

394 Such results indicate the importance of considering multiple swimming metrics when 395 quantifying a behavioral response.

Moreover, the change in helix speed and vertical translational velocity in response to 398 light indicates that larval oysters have active control over helical swimming behavior. The 399 observation that helical swimming persists in turbulence indicates a robust larval control of 
400 swimming, even in more energetic flows. Such control does not appear to be dictated by

401 morphology alone, as commonly observed in some echinoid species (Chan and Grünbaum

402 2010); larval oysters display flexibility in their helix translational and angular velocity in

403 response to environmental cues.

404

Light had no effect on the proportion of upward swimming larvae, which was surprising because we had expected to see some phototactic response in directional swimming. Despite the

407 long-established prevalence of positive phototaxis in larvae (Thorson 1964) and observations of 408 positive phototaxis in younger oyster larvae (Kennedy 1996), light had no observable effect on 409 vertical swimming direction of our late-stage larvae. Our results demonstrate that oyster larvae 410 may undergo a shift from positive to neutral phototaxis with age. Such ontogenetic changes in 411 phototaxis have been widely documented in larvae of eels (Yamada et al. 2009), polychaetes 412 (Young and Chia 1982, McCarthy et al. 2002), crabs (Forward and Costlow 1974), mussels 413 (Fuchs and DiBacco 2011), nudibranchs (Miller and Hadfield 1986), conch (Barile et al. 1994), 414 and both larval and juvenile sole (Champalbert et al. 1991). Competent larvae may cease to 415 display positive phototaxic behavior because they no longer need to stay high in the water 416 column. Further studies comparing phototactic behaviors of oyster larvae at various stages of 417 development would be required to better characterize such an ontogenetic shift. A caveat to 418 consider from our analyses, however, is the strong effect of time on larval swimming. Larvae 419 exhibited considerable behavioral shifts over the full experimental time scale, and inter-trial 420 variability may have masked an effect of light on upward swimming behavior. 
An intriguing, though unexpected, result of our study was the strong effect of larval age

423 on vertical swimming direction and dive frequency (through the trial variable). The full

424 experimental time scale encompassed approximately 12 hours, during which the competent

425 larvae persisted in culture and demonstrated all signs of good health. Our results suggest that

426 over the competency window, larval behavior can change significantly, potentially impacting

427 settlement success. In both light and dark, older larvae were less likely to swim upward in

428 turbulence than younger larvae, which might help older larvae to passively encounter settlement

429 sites. We speculate that the "young" competent-to-settle larvae in our experiment persisted in

430 upward swimming because the environmental signals they experienced (light, turbulence) did not

431 impart a strong settlement cue. The "desperate larva hypothesis", first proposed for

432 lecithotrophic larvae, suggests that young competent larvae demonstrate strong selectivity in

433 responding to potential settlement cues, but their finite energy supplies will ultimately force them

434 to accept sub-standard settlement cues (Knight-Jones 1951). An extension of this hypothesis for

435 planktotrophic larvae (like oysters) suggests that a reduced capacity to maintain the competent

436 larval swimming state over time induces larvae to settle in the absence of preferred settlement

437 cues (Botello and Krug 2006, Bishop et al. 2006). In the framework of this hypothesis,

438 turbulence might act as a sub-standard settlement cue for oyster larvae, prompting newly

439 competent larvae to persist in swimming while older larvae cease swimming in flow.

440 Alternatively, the ontogenetic shift in vertical swimming could be due to energetic constraints of

441 swimming in turbulence. Oyster larvae continue to grow throughout the competency period

442 (Wheeler, unpub. data) and older, heavier larvae may reach the point where swimming in

443 turbulence is energetically unfeasible. Because larvae are negatively buoyant, they will

444 passively sink in the water column once they cease swimming, and as such the observed decrease 
445 in upward swimming over the experimental period may be explained by the passive sinking of

446 older, heavier larvae. However, our observations demonstrate that upward swimming over time

447 only changes in turbulence, suggesting that it is a combination of turbulence and age, and not

448 merely age, which induces changes in larval swimming; in the unforced flow regime, older

449 competent larvae exhibited similar responses to newly competent larvae. In fact, both

450 interpretations (turbulence acting as a settlement cue or as an energetic constraint to swimming)

451 are supported by the observation that the effects of aging only impacted larvae swimming in

452 turbulence. The effect of age during the competency window on larval behavior may

453 furthermore explain previous conflicting results on larval oyster responses to turbulence

454 (Wheeler et al. 2013, Fuchs et al. 2013). Our results give a strong indication that ontogeny

455 should be more carefully considered in larval behavioral studies; while ontogenetic changes

456 across multiple larval stages are commonly studied, a focus on within-stage ontogenetic change

457 is rare.

Our study further strengthens the body of evidence documenting upward swimming of

460 larval oysters in moderate turbulence (Wheeler et al. 2013), which suggests that turbulence alone

461 does not act as a cue for larval settlement (with a possible exception for older, heavier, and/or

462 less selective larvae). Similarly, we observed no change in the proportion of larvae which swam

463 upward in response to light; the absence of an obvious negative phototactic response suggests

464 that neither light alone, nor light in conjunction with turbulence, are effective inducers of larval

465 settlement at a population level. Nevertheless, the observed changes in larval diving and helical

466 swimming in the presence of light suggest that they modify potentially exploratory and anti-

467 predatory behaviors in light versus darkness. Although light does not modify larval vertical 
468 swimming direction on a population level (indicative of an active settlement response), it does

469 induce behavioral changes in individuals. This shift towards exploratory swimming and rapid

470 downward responses in light is consistent with, and offers a potential behavioral mechanism for,

471 the enhanced settlement observed in the field during daylight hours. Ultimately, the importance

472 of environmental cues to larval survivorship and settlement may only become clear when

473 observing the effects of multiple drivers (like light and turbulence) on a range of larval behaviors

474 throughout an ontogenetic window.

475

476

477 Acknowledgements

478

479

We thank Susan Mills and Anthony Ritchie for experimental assistance, and Samuel

480 Laney for light measurements. We gratefully acknowledge the Aquaculture Research

481 Corporation (Dennis, MA, USA), who provided the larvae used in this study. Thanks to Jen

482 Nguyen for facilitating data transfer. Funding was provided by NSF grant OCE-0850419,

483 NOAA Sea Grant NA14OAR4170074, grants from WHOI Coastal Ocean Institute, discretionary

484 WHOI funds, a WHOI Ocean Life Fellowship to LM, a Grove City College Swezey Fund Grant

485 to EA, and a WHOI Summer Student Fellowship to EL.

486

487

488

489

490

491

492

493

494

495 

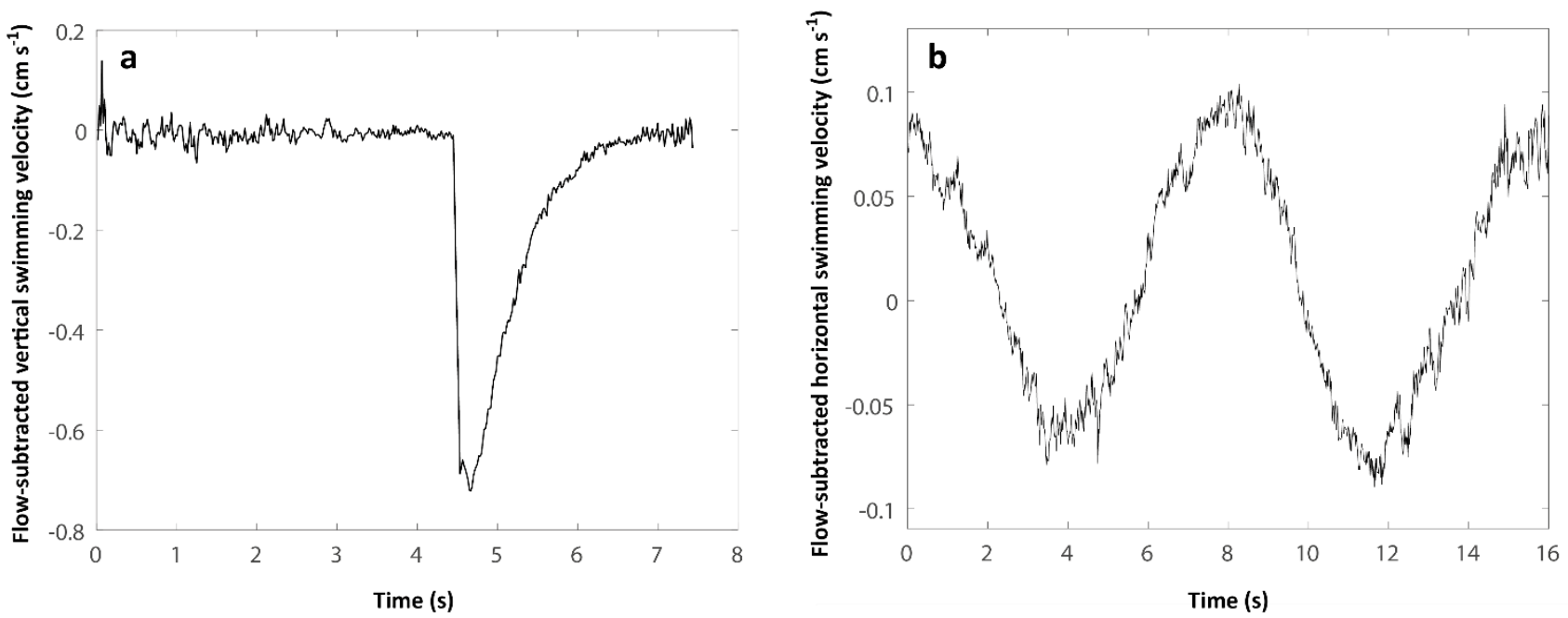

Figure 1: Distinct larval swimming behaviors observed in flow-subtracted larval swimming velocity time series at 60 frames per second, observed in a light, unforced flow regime. (a) Example of a dive, as characterized by a sudden drop in vertical velocity. In this instance, the dive occurs at $\sim 4.5 \mathrm{~s}$, with the larva achieving a downward swimming velocity of $-0.7 \mathrm{~cm} \mathrm{~s}^{-1}$. (b) Example of a helically swimming larva, characterized by a sinusoid-like shape in horizontal velocity. The period of the oscillation has a wide larva-dependent range; the $8 \mathrm{~s}$ period in this example is relatively long. 


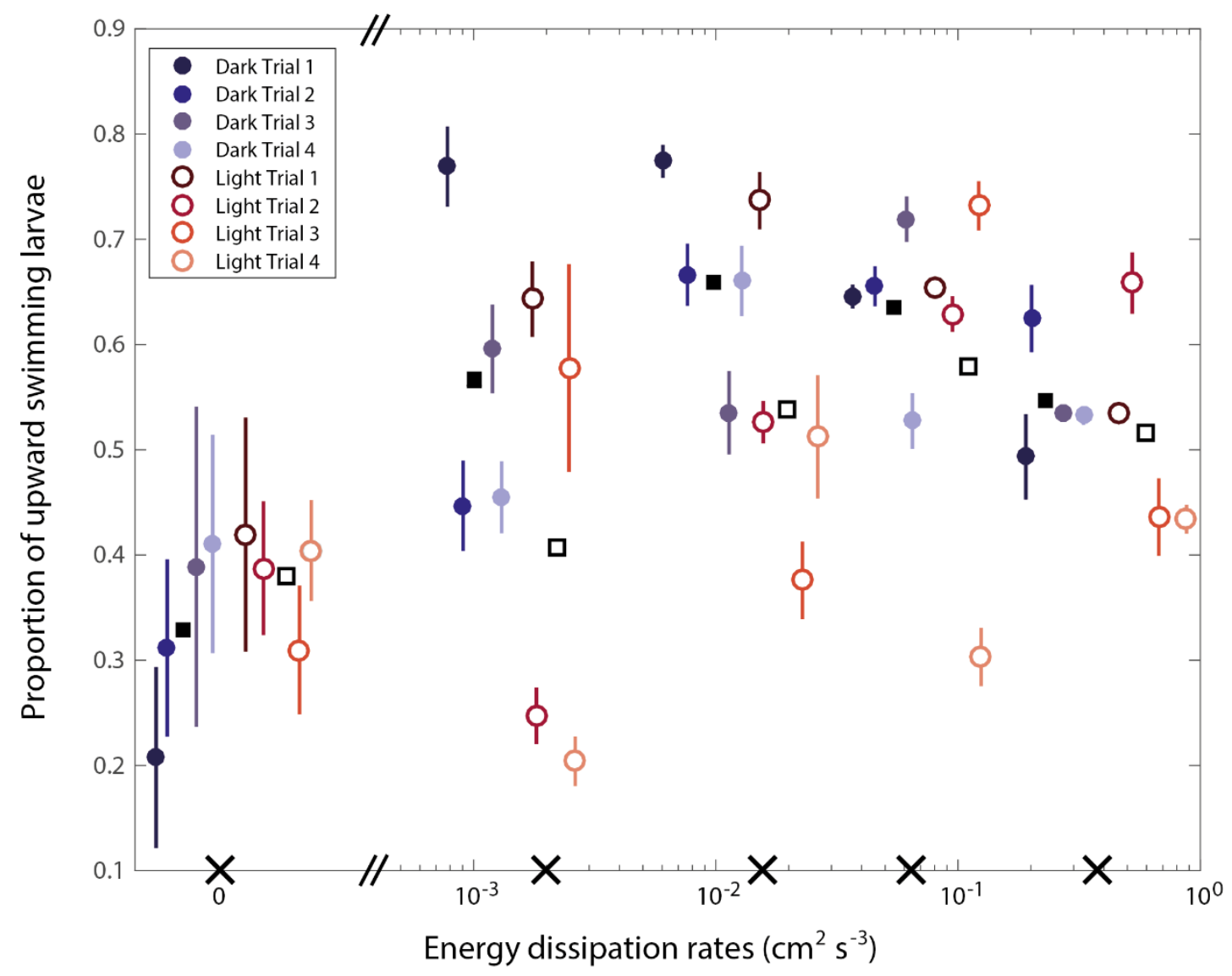

Figure 2: Mean $( \pm S E)$ proportion of upward swimming larvae for each trial vs. turbulence level (energy dissipation rate), in dark (blue-toned closed circles) and light (red-toned open circles), with trials 1-4 denoted for each by decreasing color intensity. Values at each turbulence level (denoted by $\mathrm{x}$ on the energy dissipation rate axis) are grouped by dark and light and are offset horizontally for clarity. Additionally, proportions are pooled across trial in both dark (black closed squares) and light (black open squares): as trial was a significant effect on upward swimming, these mean proportions are intended only to highlight the effects of light and turbulence. Larvae displayed primarily downward swimming in the unforced flow regime, and upward swimming in turbulence, although the prevalence of upward swimming decreased in high turbulence. Light had no significant effect on directional swimming. 


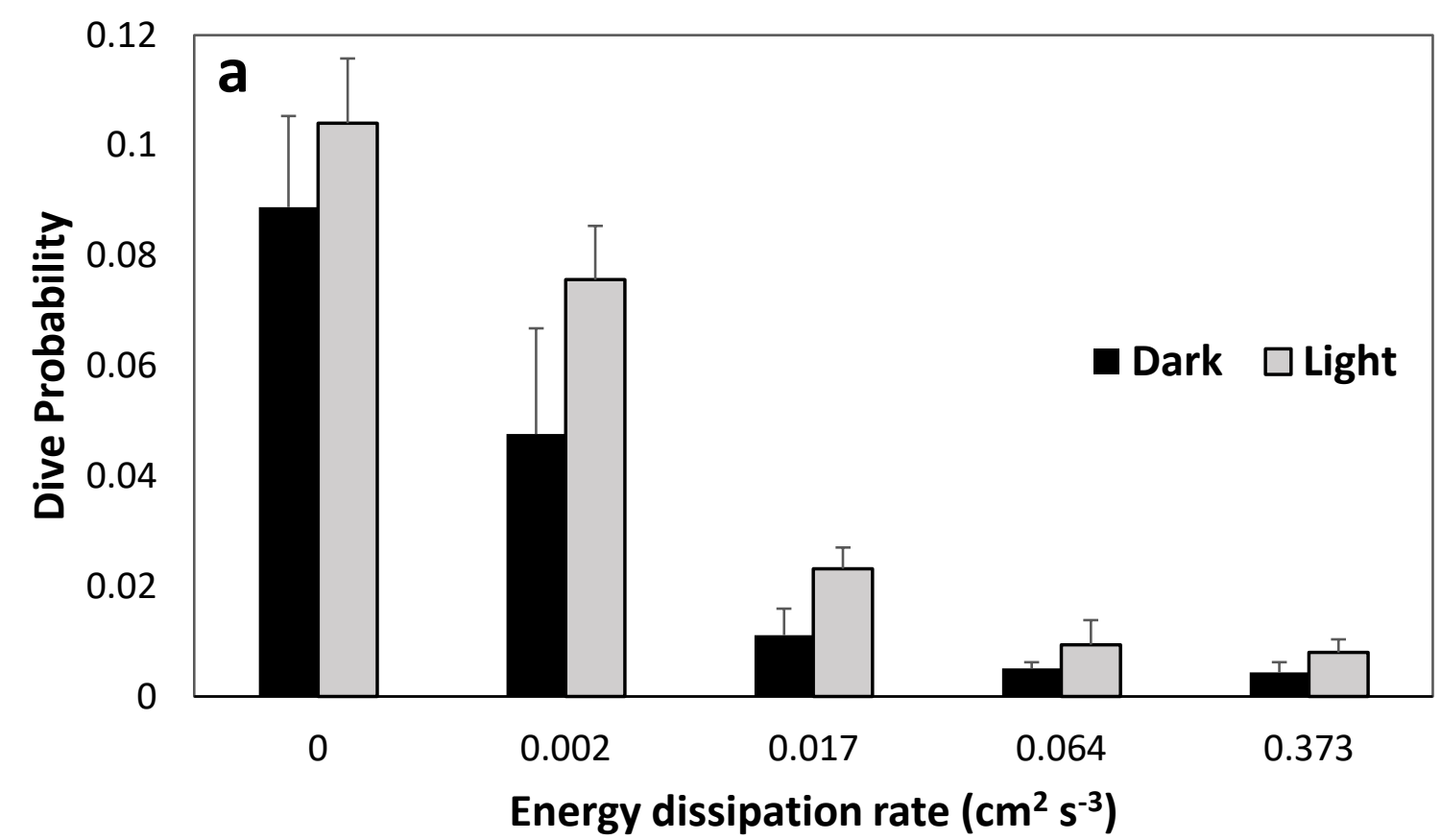

527

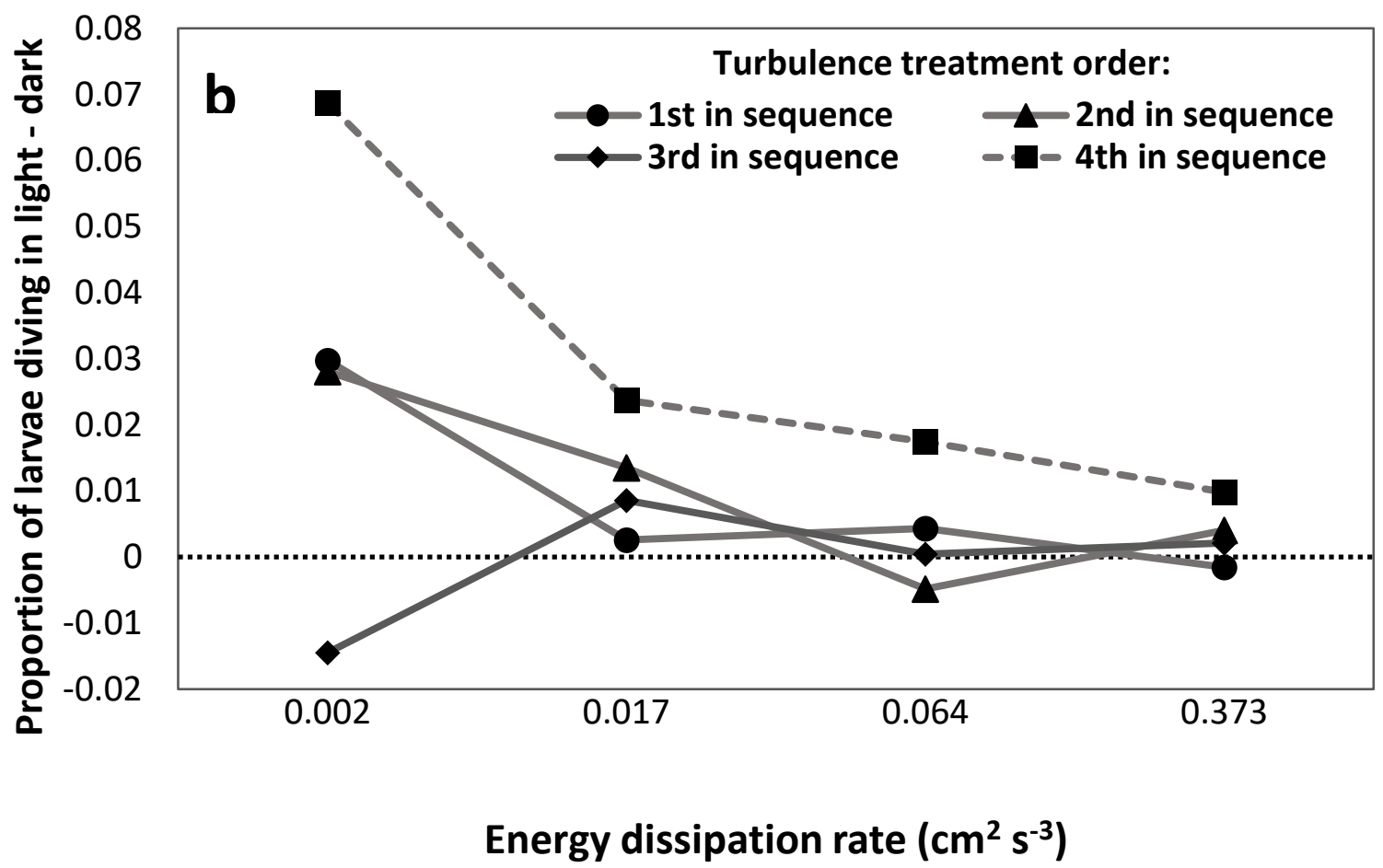

529 Figure 3: (a) Proportion of larvae diving ( \pm SE) with respect to turbulence regime, as

530 characterized by energy dissipation rate, in dark (black bars) and light (light grey bars), pooled 
across trials. Larvae exhibited increases in diving in light versus dark treatments (albeit nonsignificant) and significant decreases in diving in increasing turbulence. Note that trial is also a significant factor for diving. Pooling across trial is done to highlight other effects and trials are not treated as replicates in the analysis; SE bars are calculated for this plot using trial means and indicate the inter-trial variability. (b) Difference in the proportion of larvae diving between light and dark regimes, where a positive proportion denotes higher dive proportion in light (i.e., points denote difference between grey and black bars in (a)), with respect to turbulence regime, subdivided into turbulence treatment order. Treatment order denotes when in the sequence of four turbulence regimes a given turbulence regime fell. The dashed line denotes a significant interactive effect of treatment order and light: larvae in fourth and final turbulence treatment dive more frequently in light than dark, irrespective of what the turbulence level is, and what previous turbulence history they have experienced in the tank. Note that the lines connecting turbulence levels for each turbulence treatment order are for visual clarity in grouping treatment orders, not to imply quantitative interpolation.

7

8

0

1

2

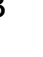

55

6

8

9

61

62

63



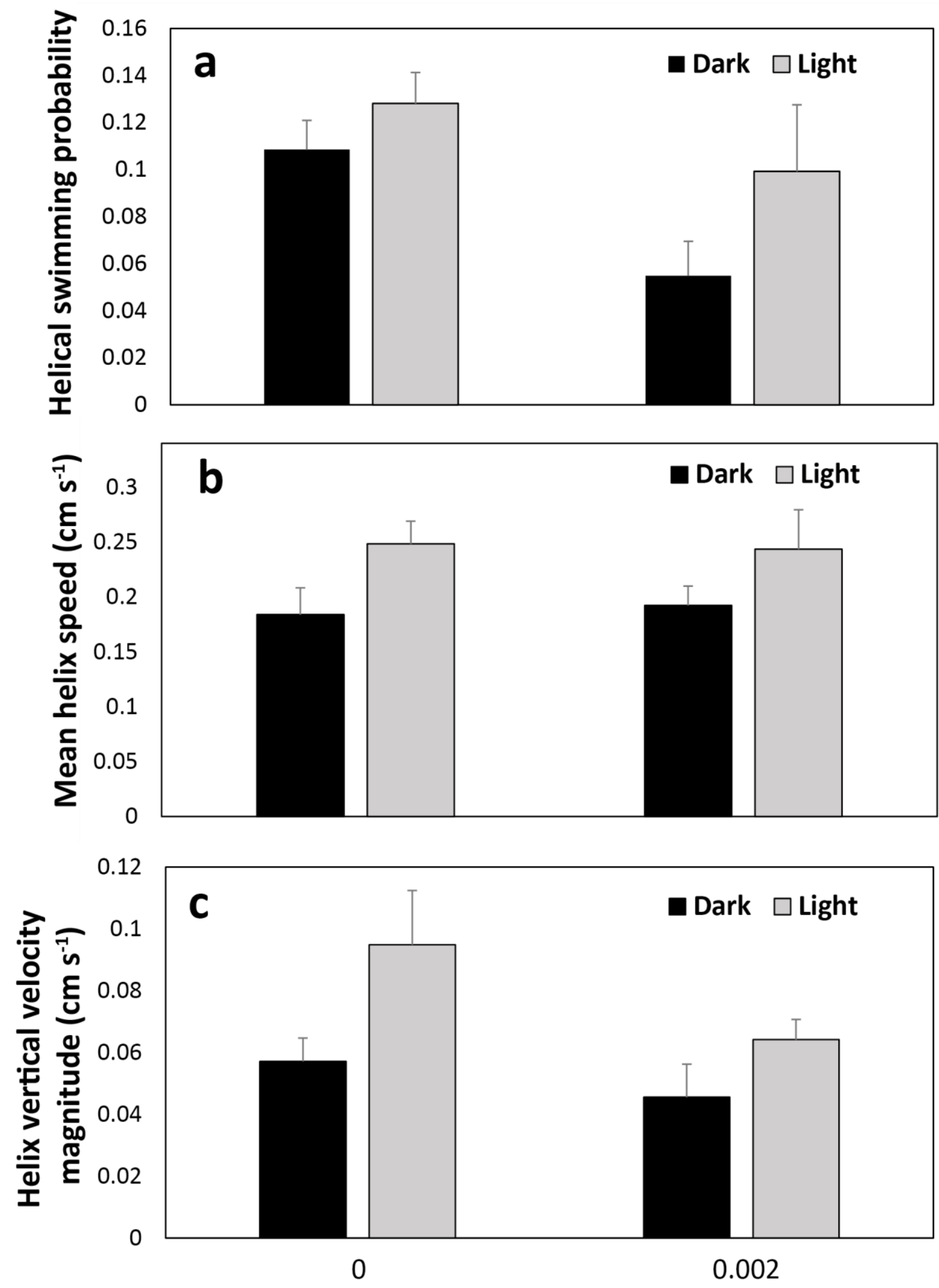

Energy dissipation rate $\left(\mathrm{cm}^{2} \mathrm{~s}^{-3}\right)$ 
Oyster larvae respond to light

566

567

568

569

570

571

572

573

574

575

576

577

578

579

580

581

582

583

584

585

586

587

588

589

590

591

592

593

594

595

596

597

598

599

600

601

602

603

604

605

606

607

608

609

610
Figure 4: (a) Proportion of larvae swimming helically, (b) helix speed, and (c) vertical translational velocity magnitude between unforced and low forcing turbulence regime , as characterized by energy dissipation rate, in dark (black bars) and light (light grey bars), pooled across trials. Trials are not treated as replicates in the analysis, but pooling by trial is done here to highlight effects of light and flow on helical behavior. SE bars are calculated using trial means and indicate the inter-trial variability. 
611

612

613

614

615

616

617

618

619

620

621

622

623

624

625

626

627

\section{Tables}

Table 1: Example of experimental design of Trial 4. Light treatments were randomized and turbulence orders were assigned by Latin square. Consult Supplemental Materials for complete experimental design of Trials 1-4 (Table S1).

\begin{tabular}{|l|l|l|l|}
\hline Treatment & $\begin{array}{l}\text { Energy dissipation } \\
\text { rate }\left(\mathbf{c m}^{\mathbf{2}} \mathbf{s}^{-3}\right)\end{array}$ & $\begin{array}{l}\text { \# 45 s } \\
\text { datasets }\end{array}$ & $\begin{array}{l}\text { \# Larvae } \\
\text { tracked }\end{array}$ \\
\hline Dark & 0 & 5 & 168 \\
Dark & 0.027 & 4 & 512 \\
Dark & 0.373 & 3 & 368 \\
Dark & 0.002 & 4 & 207 \\
Dark & 0.064 & 3 & 390 \\
& & & \\
Light & 0 & 5 & 307 \\
Light & 0.027 & 4 & 465 \\
Light & 0.373 & 3 & 737 \\
Light & 0.002 & 4 & 230 \\
Light & 0.064 & 3 & 187 \\
\hline
\end{tabular}

Table 2: Results of ANOVA for proportion of upward swimming larvae in forced flow, testing for effects of light, time (turbulence treatment order), turbulence level, and trial (aging). Significant results are bolded, with a significance level $\alpha=0.05$.

\begin{tabular}{|l|llll|}
\hline Source & $\boldsymbol{d} \boldsymbol{f}$ & MS & $\boldsymbol{F}$-ratio & $\boldsymbol{p}$-value \\
\hline Light & 1 & 0.06 & 2 & 0.21 \\
Time & 3 & 0.08 & 43.59 & $<\mathbf{0 . 0 0 1}$ \\
Turbulence level & 3 & 0.02 & 12.35 & $<\mathbf{0 . 0 0 1}$ \\
Time x Light & 3 & 0.004 & 2.05 & 0.16 \\
Turbulence level x Light & 3 & 0.006 & 3.02 & 0.07 \\
Trial (Light) & 6 & 0.03 & 15.94 & $<\mathbf{0 . 0 0 1}$ \\
Error & 12 & 0.002 & & \\
\hline
\end{tabular}

Table 3: Results of ANOVA for proportion of upward swimming larvae in unforced flow, testing for effects of light, video sequence number, and trial (aging). Significant results are bolded, with a significance level $\alpha=0.05$.

\begin{tabular}{|l|llll|}
\hline Source & $\boldsymbol{d} \boldsymbol{f}$ & MS & $\boldsymbol{F}$-ratio & $\boldsymbol{p}$-value \\
\hline Light & 1 & 0.02 & 0.95 & 0.36 \\
Video sequence & 3 & 0.1 & 3.2 & $\mathbf{0 . 0 5}$ \\
Light x Video sequence & 3 & 0.009 & 0.31 & 0.81 \\
Trial (Light) & 6 & 0.02 & 0.72 & 0.63 \\
Error & 18 & 0.03 & & \\
\hline
\end{tabular}


Table 4: Results of ANOVA for proportion of diving larvae in forced flow, testing for effects of light, time (turbulence treatment order), turbulence level, and trial (aging). Significant results are bolded, with a significance level $\alpha=0.05$.

\begin{tabular}{|l|llll|}
\hline Source & $\boldsymbol{d} \boldsymbol{f}$ & MS & $\boldsymbol{F}$-ratio & $\boldsymbol{p}$-value \\
\hline Light & 1 & 0.01 & 4.32 & 0.08 \\
Time & 3 & 0.001 & 1.27 & 0.32 \\
Turbulence level & 3 & 0.04 & 50.34 & $<\mathbf{0 . 0 0 1}$ \\
Time x Light & 3 & 0.003 & 3.99 & $\mathbf{0 . 0 3}$ \\
Turbulence level x Light & 3 & 0.0009 & 0.94 & 0.44 \\
Trial (Light) & 6 & 0.003 & 3.53 & $\mathbf{0 . 0 3}$ \\
Error & 12 & 0.0009 & & \\
\hline
\end{tabular}

Table 5: Results of ANOVA on split plots design for proportion of helically swimming larvae in unforced and low forcing flow, testing for effects of light, turbulence level, and trial (aging). Significant results are bolded, with a significance level $\alpha=0.05$.

\begin{tabular}{|l|llll|}
\hline Source & $\boldsymbol{d} \boldsymbol{f}$ & MS & $\boldsymbol{F}$-ratio & $\boldsymbol{p}$-value \\
\hline Light & 1 & 0.004 & 2.01 & 0.20 \\
Turbulence level & 1 & 0.006 & 10.68 & $\mathbf{0 . 0 2}$ \\
Turbulence level x Light & 1 & 0.0006 & 0.96 & 0.36 \\
Trial (Light) & 6 & 0.002 & 3.22 & 0.09 \\
Error & 6 & 0.0006 & & \\
\hline
\end{tabular}

Table 6: Results of ANOVA on split plots design for mean helix swimming speed in unforced and low forcing flow, testing for effects of light, turbulence level, and trial (aging). Significant results are bolded, with a significance level $\alpha=0.05$.

\begin{tabular}{|l|llll|}
\hline Source & $\boldsymbol{d} \boldsymbol{f}$ & $\mathbf{M S}$ & $\boldsymbol{F}$-ratio & $\boldsymbol{p}$-value \\
\hline Light & 1 & 0.01 & 5.02 & 0.06 \\
Turbulence level & 1 & 0.00001 & 0.005 & 0.94 \\
Turbulence level x Light & 1 & 0.0002 & 0.068 & 0.80 \\
Trial (Light) & 6 & 0.003 & 1.03 & 0.48 \\
Error & 6 & 0.003 & & \\
\hline
\end{tabular}


Oyster larvae respond to light

653

654

655

656

657

658

659

660

661

662

663

664

665

666

667

668

669

670

671

672

673

674

675

676

677

678

679

680

681

682

683

684

685

686

687

688

689

690

691

692
Table 7: Results of ANOVA on split plots design for mean helix vertical translational velocity in unforced and low forcing flow, testing for effects of light, turbulence level, and trial (aging).

Significant results are bolded, with a significance level $\alpha=0.05$.

\begin{tabular}{|l|llll|}
\hline Source & $\boldsymbol{d} \boldsymbol{f}$ & MS & $\boldsymbol{F}$-ratio & $\boldsymbol{p}$-value \\
\hline Light & 1 & 0.002 & 0.83 & 0.39 \\
Turbulence level & 1 & 0.01 & 16.4 & $\mathbf{0 . 0 0 6}$ \\
Turbulence level x Light & 1 & 0.005 & 6.72 & $\mathbf{0 . 0 4}$ \\
Trial (Light) & 6 & 0.002 & 3.98 & 0.06 \\
Error & 6 & 0.0007 & & \\
\hline
\end{tabular}


Oyster larvae respond to light

693

694

695

696

697

\section{Supplementary Materials}

Table S1: Experimental design: Light treatments were randomized and turbulence orders were assigned by Latin square in an attempt to minimize the effects of time.

\begin{tabular}{|c|c|c|c|c|}
\hline Trial & Treatment & $\begin{array}{l}\text { Turbulence } \\
\text { level }\left(\mathrm{cm}^{2} \mathrm{~s}^{-3}\right)\end{array}$ & $\begin{array}{l}\text { Number of } 45- \\
\text { second datasets }\end{array}$ & $\begin{array}{c}\text { Number of } \\
\text { larvae tracked }\end{array}$ \\
\hline 1 & dark & 0 & 5 & 69 \\
\hline 1 & dark & 0.002 & 4 & 133 \\
\hline 1 & dark & 0.027 & 4 & 464 \\
\hline 1 & dark & 0.064 & 3 & 409 \\
\hline 1 & dark & 0.373 & 3 & 379 \\
\hline 1 & light & 0 & 5 & 91 \\
\hline 1 & light & 0.002 & 4 & 191 \\
\hline 1 & light & 0.027 & 4 & 450 \\
\hline 1 & light & 0.064 & 3 & 566 \\
\hline 1 & light & 0.373 & 3 & 510 \\
\hline 2 & light & 0 & 5 & 298 \\
\hline 2 & light & 0.373 & 3 & 896 \\
\hline 2 & light & 0.064 & 3 & 967 \\
\hline 2 & light & 0.027 & 4 & 767 \\
\hline 2 & light & 0.002 & 4 & 323 \\
\hline 2 & dark & 0 & 5 & 91 \\
\hline 2 & dark & 0.373 & 3 & 376 \\
\hline 2 & dark & 0.064 & 3 & 330 \\
\hline 2 & dark & 0.027 & 4 & 424 \\
\hline 2 & dark & 0.002 & 4 & 237 \\
\hline 3 & light & 0 & 5 & 220 \\
\hline 3 & light & 0.064 & 3 & 604 \\
\hline 3 & light & 0.002 & 4 & 215 \\
\hline 3 & light & 0.373 & 3 & 343 \\
\hline 3 & light & 0.027 & 4 & 382 \\
\hline 3 & dark & 0 & 5 & 68 \\
\hline 3 & dark & 0.064 & 3 & 430 \\
\hline 3 & dark & 0.002 & 4 & 210 \\
\hline 3 & dark & 0.373 & 3 & 301 \\
\hline 3 & dark & 0.027 & 4 & 398 \\
\hline 4 & dark & 0 & 5 & 168 \\
\hline 4 & dark & 0.027 & 4 & 512 \\
\hline 4 & dark & 0.373 & 3 & 368 \\
\hline 4 & dark & 0.002 & 4 & 207 \\
\hline 4 & dark & 0.064 & 3 & 390 \\
\hline 4 & light & 0 & 5 & 307 \\
\hline 4 & light & 0.027 & 4 & 465 \\
\hline
\end{tabular}




\begin{tabular}{|l|l|l|l|l|}
\hline 4 & light & 0.373 & 3 & 737 \\
\hline 4 & light & 0.002 & 4 & 230 \\
\hline 4 & light & 0.064 & 3 & 487 \\
\hline
\end{tabular}

Table S2: Post-hoc Tukey's HSD test of differences in mean proportion of upward swimming larvae in flow, with respect to turbulence level, using least squares means and $d f=12$. Significant results are bolded, with a significance level $\alpha=0.05$.

\begin{tabular}{|l|lll|}
\hline Turbulence levels $\left(\mathbf{c m}^{\mathbf{2}} \mathbf{~ s}^{\mathbf{- 3}}\right)$ & Difference & p-value & $\mathbf{9 5 \%}$ CIS \\
\hline 0.002 vs 0.027 & -0.11 & $\mathbf{0 . 0 0 2}$ & {$[-0.17,-0.04]$} \\
0.002 vs 0.064 & -0.12 & $\mathbf{0 . 0 0 1}$ & {$[-0.18,-0.05]$} \\
0.002 vs 0.373 & -0.04 & 0.35 & {$[-0.10,0.02]$} \\
0.027 vs 0.064 & -0.01 & 0.97 & {$[-0.08,0.06]$} \\
0.027 vs 0.373 & 0.07 & $\mathbf{0 . 0 4}$ & {$[0.001,0.133]$} \\
0.064 vs 0.373 & 0.08 & $\mathbf{0 . 0 2}$ & {$[0.01,0.14]$} \\
\hline
\end{tabular}

Table S3: Post-hoc Tukey's HSD test of differences in mean proportion of upward swimming larvae in flow, with respect to time within a trial, using least squares means and $d f=12$.

Significant results are bolded, with a significance level $\alpha=0.05$. The time comparisons here, $i$ vs $j$, refer to the $i^{\text {th }}$ and $j^{\text {th }}$ times of four possible times in the treatment order.

\begin{tabular}{|l|lll|}
\hline Times & Difference & p-value & $\mathbf{9 5 \%}$ CIS \\
\hline 1 vs 2 & 0.05 & 0.19 & {$[-0.02,0.11]$} \\
1 vs 3 & 0.15 & $<\mathbf{0 . 0 0 1}$ & {$[0.08,0.22]$} \\
1 vs 4 & 0.23 & $<\mathbf{0 . 0 0 1}$ & {$[0.17,0.30]$} \\
2 vs 3 & 0.10 & $\mathbf{0 . 0 0 3}$ & {$[0.04,0.16]$} \\
2 vs 4 & 0.18 & $<\mathbf{0 . 0 0 1}$ & {$[0.12,0.25]$} \\
3 vs 4 & 0.08 & $\mathbf{0 . 0 1}$ & {$[0.02,0.15]$} \\
\hline
\end{tabular}

Table S4: Post-hoc Tukey's HSD test of differences in mean proportion of upward swimming larvae in unforced flow, with respect to video sequence number, using least squares means and $d f=18$. Significant results are bolded, with a significance level $\alpha=0.05$.

\begin{tabular}{|l|lll|}
\hline Video Sequences & Difference & p-value & 95\% CIS \\
\hline 1 vs 2 & 0.08 & 0.81 & {$[-0.16,0.32]$} \\
1 vs 3 & -0.12 & 0.47 & {$[-0.37,0.11]$} \\
1 vs 4 & -0.16 & 0.30 & {$[-0.40,0.09]$} \\
2 vs 3 & -0.20 & 0.12 & {$[-0.45,0.04]$} \\
2 vs 4 & -0.23 & 0.07 & {$[-0.48,0.01]$} \\
3 vs 4 & -0.02 & 0.99 & {$[-0.27,0.22]$} \\
\hline
\end{tabular}


Table S5: Post-hoc Tukey's HSD test of differences in mean dive proportion in flow, with respect to turbulence level, using least squares means and $d f=12$. Significant results are bolded, with a significance level $\alpha=0.05$.

\begin{tabular}{|l|lll|}
\hline Turbulence levels $\left(\mathbf{c m}^{\mathbf{2}} \mathbf{~}^{\mathbf{3}}\right)$ & Difference & $\mathbf{p}$-value & $\mathbf{9 5 \%}$ CIS \\
\hline 0.002 vs 0.027 & 0.12 & $\mathbf{0 . 0 0 1}$ & {$[0.07,0.16]$} \\
0.002 vs 0.064 & 0.16 & $<\mathbf{0 . 0 0 1}$ & {$[0.11,0.21]$} \\
0.002 vs 0.373 & 0.17 & $<\mathbf{0 . 0 0 1}$ & {$[0.12,0.22]$} \\
0.027 vs 0.064 & 0.04 & 0.06 & {$[-0.002,0.09]$} \\
0.027 vs 0.373 & 0.05 & $\mathbf{0 . 0 2}$ & {$[0.008,0.10]$} \\
0.064 vs 0.373 & 0.01 & 0.92 & {$[-0.03,0.05]$} \\
\hline
\end{tabular}

Table S6: Post-hoc Tukey's HSD test of differences in mean dive proportion in flow, with respect to interactive light and time within a trial, using least squares means and $d f=12$. Significant results are bolded, with a significance level $\alpha=0.05$. The time comparisons here, $i$ vs $j$, refer to the $i^{\text {th }}$ and $j^{\text {th }}$ times of four possible times in the treatment order, while ' $\mathrm{L}$ ' and ' $\mathrm{D}$ ' refer to the light and dark treatments, respectively.

\begin{tabular}{|l|lll|}
\hline Light x Time & Difference & p-value & $\mathbf{9 5 \%}$ CIS \\
\hline Dark Only & & & \\
D1 vs D2 & 0.02 & 0.95 & {$[-0.06,0.10]$} \\
D1 vs D3 & -0.02 & 0.98 & {$[-0.10,0.06]$} \\
D1 vs D4 & 0.04 & 0.54 & {$[-0.04,0.12]$} \\
D2 vs D3 & -0.04 & 0.55 & {$[-0.12,0.04]$} \\
D2 vs D4 & 0.02 & 0.98 & {$[-0.06,0.10]$} \\
D3 vs D4 & 0.06 & 0.17 & {$[-0.02,0.14]$} \\
\hline Light Only & & & \\
L1 vs L2 & 0.01 & 0.99 & {$[-0.07,0.09]$} \\
L1 vs L3 & -0.007 & 0.99 & {$[-0.09,0.07]$} \\
L1 vs L4 & -0.04 & 0.56 & {$[-0.12,0.04]$} \\
L2 vs L3 & -0.02 & 0.98 & {$[-0.10,0.06]$} \\
L2 vs L4 & -0.05 & 0.31 & {$[-0.13,0.03]$} \\
L3 vs L4 & -0.04 & 0.73 & {$[-0.11,0.04]$} \\
\hline Dark vs Light & & & \\
D1 vs L1 & -0.02 & 0.97 & {$[-0.10,0.06]$} \\
D1 vs L2 & -0.01 & 0.99 & {$[-0.09,0.07]$} \\
D1 vs L3 & -0.03 & 0.89 & {$[-0.11,0.05]$} \\
D1 vs L4 & -0.06 & 0.15 & {$[-0.14,0.02]$} \\
D2 vs L1 & -0.05 & 0.49 & {$[-0.12,0.03]$} \\
D2 vs L2 & -0.03 & 0.77 & {$[-0.11,0.05]$} \\
D2 vs L3 & -0.05 & 0.34 & {$[-0.13,0.03]$} \\
D2 vs L4 & -0.09 & $\mathbf{0 . 0 3}$ & {$[-0.17,-0.008]$} \\
D3 vs L1 & -0.003 & 1.00 & {$[-0.08,0.07]$} \\
D3 vs L2 & 0.009 & 0.99 & {$[-0.07,0.08]$}
\end{tabular}




\begin{tabular}{|llll|} 
D3 vs L3 & -0.01 & 0.99 & {$[-0.09,0.07]$} \\
D3 vs L4 & -0.04 & 0.50 & {$[-0.12,0.03]$} \\
D4 vs L1 & -0.06 & 0.14 & {$[-0.14,0.01]$} \\
D4 vs L2 & -0.05 & 0.30 & {$[-0.13,0.03]$} \\
D4 vs L3 & -0.07 & 0.09 & {$[-0.15,0.01]$} \\
D4 vs L4 & -0.11 & $\mathbf{0 . 0 0 6}$ & {$[-0.17,-0.03]$} \\
\hline
\end{tabular}

731

732

733

734

735

736

737

738

739

740

741

742

743

744

745

746

747

748

749

750

751

752

753

754

755

756

757

758
Table S7: Post-hoc Tukey's HSD test of differences in mean helix translational velocity in unforced and low forcing flow, with respect to interactive light and turbulence level, using least squares means and $d f=6$. Significant results are bolded, with a significance level $\alpha=0.05$. The numbers associated with the turbulence levels are the reported energy dissipation rates for each flow regime (in $\mathrm{cm}^{2} \mathrm{~s}^{-3}$ ), while ' $\mathrm{L}$ ' and ' $\mathrm{D}$ ' refer to the light and dark treatments, respectively.

\begin{tabular}{|l|lll|}
\hline Turbulence level x Light & Difference & p-value & 95\% CIS \\
\hline D0 vs D0.002 & -0.09 & $\mathbf{0 . 0 1}$ & {$[-0.16,-0.02]$} \\
L0 vs L0.002 & -0.02 & 0.74 & {$[-0.09,0.05]$} \\
D0 vs L0 & -0.06 & 0.07 & {$[-0.13,0.007]$} \\
D0 vs L0.002 & -0.08 & $\mathbf{0 . 0 2}$ & {$[-0.14,-0.01]$} \\
D0.002 vs L0 & 0.03 & 0.45 & {$[-0.10,0.04]$} \\
D0.002 vs L0.002 & 0.01 & 0.94 & {$[-0.06,0.08]$} \\
\hline
\end{tabular}


Oyster larvae respond to light

\section{References}

Barile PJ, Stoner AW, Young CM (1994) Phototaxis and vertical migration of the queen conch (Strombus gigas linne) veliger larvae. J of Exp Mar Bio Ecol 183(2):147-162

Bartol IK, Mann R, Luckenbach M (1999) Growth and mortality of oysters (Crassostrea virginica) on constructed intertidal reefs: effects of tidal height and substrate level. J Exp Mar Biol Ecol 237:157-184

Bingham BL, Young CM (1993) Larval phototaxis in barnacles and snails associated with bathyal sea urchins. Deep-Sea Res Part I. 40(1):1-12

Bishop CD, Huggett MJ, Heyland A, Hodin J, Brandhorst BP (2006) Interspecific variation in metamorphic competence in marine invertebrates: the significance for comparative investigations into the timing of metamorphosis. Integr Comp Biol. 46(6): 662-682.

Botello G, Krug PJ (2006) Desperate larvae revisited: age, energy and experience affect sensitivity to settlement cues in larvae of the gastropod Alderia sp. Mar Ecol Prog Ser 312:149-159

Breitburg DL, Coen LD, Luckenbach MW, Mann R, Posey M, Wesson JA (2000) Oyster reef restoration: convergence of harvest and conservation strategies. J Shellfish Res 19:371-377

Butman CA (1987) Larval settlement of soft-sediment invertebrates: the spatial scales of pattern explained by active habitat selection and the emerging role of hydrodynamical processes. Oceanogr Mar Biol Annu Rev 25:113-165

Champalbert G, Macquart-Moulin C, Patriti G, Chiki D (1991) Ontogenic variations in the phototaxis of larval and juvenile sole Solea solea L. J Exp Mar Bio Ecol 149(2):207-225

Chan KYK, Grünbaum D (2010) Temperature and diet modified swimming behaviors of larval sand dollar. Mar Ecol Prog Ser 415:49-59

Currin CA, Chappell WS, Deaton A (2010) Developing alternative shoreline armoring strategies: the living shoreline approach in North Carolina, in Shipman, H, Dethier MN, Gelfenbaum G, Fresh KL, and Dinicola RS, eds., 2010 Puget Sound Shorelines an the Impacts of Armoring Proceedings of a State of the Science Workshop, May 2009. US Geological Survey Scientific Investigations Report 2010-5254, p. 91-102.

Forward RB, Costlow JD (1974) The ontogeny of phototaxis by larvae of the crab Rhithropanopeus harrisii. Mar Bio 26(1):27-33

, Cronin TW (1980) Tidal rhythms in activity and phototaxis by an estuarine crab larva. Bio Bull 158: 295-303

Fredriksson DW, Steppe CN, Wallendorf L, Sweeney S, Kriebel D (2010) Biological and hydrodynamic design considerations for vertically oriented oyster grow out structures. Aquacult Eng 42:57-69 
Oyster larvae respond to light

806

807

808

809

810

811

812

813

814

815

816

817

818

819

820

821

822

823

824

825

826

827

828

829

830

831

832

833

834

835

836

837

838

839

840

841

842

843

844

845

846

847

848

849

850

851

852

853

854

855

Frouin R, McPherson J, Ueyoshi K, Franz BA (2012) A timeseries of photo-synthetically available radiation at the ocean surface from SeaWiFS and MODIS data. In: Frouin RJ, Ebuchi N, Pan D, Saino T (eds) Remote Sensing of the Marine Environment II. Proc of SPIE 8525.

Fuchs HL, DiBacco C (2011) Mussel larval responses to turbulence are unaltered by larval age or light conditions. Limn Oceanogr: Fluids Env 1(2011):120-134

Fuchs HL, Hunter EJ, Schmitt EL, Guazzo RA (2013) Active downward propulsion by oyster larvae in turbulence. J Exp Bio 216,1458-1469

Hidu H, Haskin H (1978) Swimming speeds of oyster larvae Crassostrea virginica in different salinities and temperatures. Estuar Coast 1(4): 252-255

Helm MM, Bourne N, Lovatelli A (2004) Hatchery operation: Culture of larvae, basic methodology, feeding and nutrition, factors influencing growth and survival, and settlement and metamorphosis. In: Helm MM, Bourne N, Lovatelli A (eds) Hatchery Culture of Bivalves: A Practical Manual. FAO Fisheries Technical Paper 471, FAO Rome. p. 84-129.

Iwasa Y (1982) Vertical migration of zooplankton: a game between predator and prey. Am Nat 120(2):171-180

Jakobsen, H (2001). Escape response of planktonic protists to fluid mechanical signals. Mar Ecol Prog Ser 214:67-78

Jékely G (2009) Evolution of phototaxis. R Soc Lond B Bio Sci 364(1531):2795-2808

Jékely G, Colombelli J, Hausen H, Guy K, Stelzer E, Nédélec F, Arendt D (2008) Mechanism of phototaxis in marine zooplankton. Nature 456(7220):395-399

Jonsson PR, Andre C, Lindegarth M (1991) Swimming behavior of marine bivalve larvae in a flume boundary-layer flow: evidence for near-bottom confinement. Mar Ecol Prog Ser 79:67-76

Kemp WM, Boynton WR, Adolf JE, Boesch DF, others (2005) Eutrophication of Chesapeake Bay: historical trends and ecological interactions. Mar Ecol Prog Ser 303:1-29

Kennedy VS (1996) Biology of larvae and spat. In: Kennedy VS, Newell RIE Eble AF (eds) The Eastern Oyster Crassostrea virginica. Maryland Sea Grant College, University of Maryland, College Park, Maryland. p 371-421

Kim CK, Park K, Powers SP (2013). Establishing restoration strategy of eastern oyster via a coupled biophysical transport model. Restor Ecol 21(3):353-362

Kiørboe T, Saiz E, Visser A (1999). Hydrodynamic signal perception in the copepod Acartia tonsa. Mar Ecol Prog Ser 97-111

Knight-Jones EW (1951). Gregariousness and some other aspects of the setting behaviour of Sipirorbis. J Mar Biol Assoc UK 30(2): 201-222.

Lillis A, Eggleston DB, Bohnenstiehl DR (2013) Oyster larvae settle in response to habitat-associated underwater sounds. PLoS ONE 8(10): e79337 
Oyster larvae respond to light

856

857

858

859

860

861

862

863

864

865

866

867

868

869

870

871

872

873

874

875

876

877

878

879

880

881

882

883

884

885

886

887

888

889

890

891

892

893

894

895

896

897

898

899

900

901

902

903

McCarthy DA, Forward RB Jr., Young CM (2002) Ontogeny of phototaxis and geotaxis during larval development of the sabellariid polychaete Phragmatopoma lapidosa. Mar Ecol Prog Ser 241:215220

Metaxas A, Saunders M (2009) Quantifying the "bio-" components in biophysical models of larval transport in marine benthic invertebrates: advances and pitfalls. Biol Bull 216(3)-257-272

Miller SE, Hadfield MG (1986) Ontogeny of phototaxis and metamorphic competence in larvae of the nudibranch Phestilla sibogae Bergh (Gastropoda:Opisthobranchia). J Exp Mar Bio Ecol 97(1):95112

Nelson KA, Leonard LA, Posey MH, Alphin TD, Mallin MA (2004) Using transplanted oyster (Crassostrea virginica) beds to improve water quality in small tidal creeks: a pilot study. J Exp Mar Biol Ecol 298:347-368

Nestlerode JA, Luckenbach ML, O'Beirn FX (2007) Settlement and survival of the oyster Crassostrea virginica on created oyster reef habitats in Chesapeake Bay. Restor Ecol 15:273-283

Newell RIE (1988) Ecological changes in Chesapeake Bay: are they the result of over harvesting the American oyster, Crassostrea virginica? In: Lynch MP, Krome EC (eds) Understanding the estuary: advances in Chesapeake Bay research. Chesapeake Research Consortium Publications 129, Baltimore, MD, 536-546

NOAA Fisheries Eastern Oyster Review Team (2007) Status Review of the Eastern Oyster (Crassostrea Virginica). NOAA Technical Memorandum NMFS-F/SPO-88

North E, Schlag Z, Hood R, Li M, Zhong L, Gross T, Kennedy VS (2008) Vertical swimming behavior influences the dispersal of simulated oyster larvae in a coupled particle-tracking and hydrodynamic model of Chesapeake Bay. Mar Ecol Prog Ser 359: 99-115

Pepper RE, Jaffe JS, Variano E, Koehl MAR (2015) Zooplankton in flowing water near benthic communities encounter rapidly fluctuating velocity gradients and accelerations. Mar Biol 162(10):1939-1954

Rothschild BJ, Ault JS, Goulletquer P, Heral M (1994) Decline of the Chesapeake Bay oyster population: a century of habitat destruction and overfishing. Mar Ecol Prog Ser 111:29-39

Svane, I. and C.M. Young (1989) The ecology and behavior of ascidian larvae. Oceanography and Marine Biology, Annual Review 27:45-90

Tamburri M, Finelli C, Wethey D, Zimmer-Faust R (1996) Chemical induction of larval settlement behavior in flow. Bio Bull 191: 367-373

Thompson R, Newell RIE, Kennedy VS, Mann R (1996) Reproductive processes and early development in Kennedy VS, and Newell RIE, Eble AF (eds) The Eastern Oyster (Crassostrea Virginica). Maryland Sea Grant. p 335-370. 
Oyster larvae respond to light

904

905

906

907

908

909

910

911

912

913

914

915

916

917

918

919

920

921

922

923

924

925

926

927

928

929

930
Thorson G (1964) Light as an ecological factor in the dispersal and settlement of larvae of marine bottom invertebrates. Orphelia 1:167-208

Vazquez E, Young CM (1998) Ontogenetic changes in phototaxis during larval life of the Ascidian Polyandrocarpa Zorritensis. J Exp Mar Biol Ecol 231(2):267-77

Visser A (2007) Motility of zooplankton: Fitness, foraging, and predation. J Plank Res 29(5):447-461

Wheeler JD, Helfrich KR, Anderson EJ, McGann B, Staats P, Wargula AE, Wilt K, and Mullineaux LS (2013) Upward swimming of competent oyster larvae (Crassostrea virginica) persists in highly turbulent flow as detected by PIV flow subtraction. Mar Ecol Prog Ser 488:171-185

Wheeler JD, Helfrich KR, Anderson EJ, Mullineaux (2015) Isolating the hydrodynamic triggers of the dive response in eastern oyster larvae. Limn Oceanogr 60: 1332-1343.

Whitman ER, Reidenbach MA (2012) Benthic flow environment affect recruitment of Crassostrea virginica larvae to an intertidal oyster reef. Mar Ecol Prog Ser 463:177-191

Wu RSS, Lam PKS, Zhou BS (1997) A phototaxis inhibition assay using barnacle larvae. Env Tox Water Qual 12(3):231-236

Yamada Y, Okamura A, Mikawa N, Utoh T, Horie N, Tanaka S, Miller MJ, Tsukamoto K (2009) Ontogenetic changes in phototactic behavior during metamorphosis of artificially reared Japanese eel Anguilla japonica larvae. Mar Ecol Prog Ser 379:241-251

Young CM, Chia FS (1982) Ontogeny of phototaxis during larval development of the sedentary polychaete, Serpula vermicularis (L.). Bio Bull 162(3):457-468 